\title{
International Organizations and the Architecture of Arguments in Global Social Governance
}

\author{
Kerstin Martens, Dennis Niemann, \\ and Alexandra Kaasch
}

This book has dealt with the initiatives, ideas, and policy preferences of International Organizations (IOs) in different fields of global social policy. The chapters have focused on fields within the broader areas of labor and

This chapter is a product of the research conducted in the Collaborative Research Center "Global Dynamics of Social Policy" at the University of Bremen. The center is funded by the Deutsche Forschungsgemeinschaft (DFG, German Research Foundation)—project number 374666841—SFB 1342.

K. Martens $(\bowtie) \bullet$ D. Niemann

Institute for Intercultural and International Studies (InIIS) and Collaborative Research Centre 1342 "Global Dynamics of Social Policy", University of Bremen, Bremen, Germany e-mail: martensk@uni-bremen.de; dniemann@uni-bremen.de

A. Kaasch

Faculty of Sociology, Bielefeld University, Bielefeld, Germany e-mail: alexandra.kaasch@uni-bielefeld.de

(C) The Author(s) 2021

K. Martens et al. (eds.), International Organizations in Global

Social Governance, Global Dynamics of Social Policy, https://doi.org/10.1007/978-3-030-65439-9_14 
migration, family and education, and health and environment. Each contribution has provided specific accounts of actor constellations, ideational content, and resulting characterizations of global social policy architectures. In this final chapter, we aim to bring together in a systematic manner the insights from these various social policy fields in order to generalize about populations of IOs, ideas and discourses, and patterns of global governance in social policies.

Naturally, most of the chapters in the volume acknowledge that the fields being looked at are driven by many different global actors, with IOs being just one, albeit a central one. None of the chapters nor this conclusion suggest that IOs are always the most important or most powerful actors. Nevertheless, they can be considered the most multi-faceted type of actor, in particular due to their multiple and varying roles, functions, and mechanisms of impact. By IOs we refer to intergovernmental organizations which have their own organizational bodies (e.g. secretariats) and have states as their prime members. Other types of organizations (e.g. bi- or multilateral associations of international exchange or international non-governmental organizations) are mentioned and discussed in relation to and within the context of IOs. In conceptualizing global social governance within social fields, we were interested in mapping each field according to the IOs active in it and analyzing the discourses they promote. The analytical approaches of organizational ecology and of soft governance within the study of IR were loosely applied in this volume as heuristic frames and offered a theoretical lens for assessing the developments in the social policy fields. First, each chapter in this book shed light on IO involvement in a particular social policy field by describing the population of engaging IOs, namely how a field is constituted as well as which are the major or regional IOs. Second, each chapter examined the discourses within and between the IOs of a respective field, presenting the major leitmotifs and policies found in a field. Overall, the chapters described and analyzed what we call the architecture of arguments in global social governance.

This concluding chapter resumes the arguments made in the introduction to this volume. We highlight prevailing cross-cutting issues and themes by summarizing findings pertinent to the different questions we raised in the introduction: How is the field of IOs in global social governance constituted? How can the discourses of IOs in social policy fields be described? How is the constellation of IOs interlinked with what they address? IOs have actively shaped the architecture of arguments in global social governance for a long time: They have populated diverse social fields and exercised soft governance, shaping how the global discourse on social policy topics is organized through the cognitive authority they hold over 
their specific field. While the dynamics within populations tend to be characterized by cooperation and coexistence, looking at the discourses and ideas promoted in social policy reveals contestation between IOs. This chapter closes by formulating avenues for further research.

\section{IO Populations in Global Social Policies}

The previous chapters mapped the population of IOs in a given social policy field by assessing the organizational fields in the realm of social policy. They showed which actors were pivotal and how the composition of IOs dealing with a certain policy evolved. Some IOs appear in almost all social policy fields. This group of almost omnipresent IOs includes the International Labour Organization (ILO) and the World Bank in particular, and increasingly also the Organisation for Economic Co-operation and Development (OECD) to a certain extent. Therefore, these three IOs can be considered as general global social policy actors, working across a significant variety and number of specific social policy areas. This is not fundamentally new or surprising. Studies from as early as the 1990s onward have placed the ILO and the World Bank at the center of explaining global social policies and governance (Deacon 2007; Deacon et al. 1997). Equally significant in more recent years has been the OECD, which made notable contributions to the field and is considered a key global social policy actor (see also Deeming and Smyth 2018; Deacon and Kaasch 2008; Kaasch 2010; Ervik 2009; Mahon 2009). This observation holds true even for most of the policy fields that have barely been addressed by the global social policy literature before.

Also in line with earlier works (Deacon et al. 1997), all chapters have shown how the UN system is a structural determinant of global social policy fields. Particularly the overarching Millennium Development Goals (MDGs), as well as the Sustainable Development Goals (SDGs) as global initiatives on the UN level, are mechanisms that bring IO actors together in their commitments to achieve common goals. That has been specifically mentioned in several chapters, for example, by Lakeman on climate change or by Wolkenhauer on food.

With regard to single IOs, the oldest one is also one of the most significant and visible organizations in social policy: the ILO. Mandated with labor market and social protection issues and uniquely comprised in a tripartite manner of governments, employers, and workers, the ILO appears as a key player in any global social policy field. In many of the chapters, the story repeats itself: the World Bank appeared on the scene in the 1990s, 
challenging the ILO (and other UN agencies) and taking on quite a powerful role from that point on (apart from Deacon's work; Koivusalo and Ollila 1997 made such an argument for the field of health; Mundy and Verger 2015 for education). Similarly, the OECD emerged as an influential actor in social policy. While this IO is significantly different due to it having a limited number of member states and therefore a rather indirect impact on most countries of the world, its ideational and discursive power has also challenged UN specialized agencies (see, e.g. some of the contributions in Mahon and McBride 2008).

Several major and globally acting IOs, like the ILO, the World Bank, and the OECD, successively expanded their social policy portfolios and populated niches which were previously not occupied by IOs. This, among other things, resulted in what Deacon (2007) had called 'overlapping' and 'competing' institutions in the shorter term. In the longer term, however, much of this has turned into collaborative relationships under joint goals or initiatives. In this way, as within the UN system particularly, the ILO and the World Bank were able to take leading positions in wider initiatives, keep powerful positions over extended time periods-even when faced with more IOs as actors in the field-and set the tone for as well as play a dominant role in shaping the global discourse. This can be seen, for example, in the context of the Social Protection Floor initiative, as mentioned by Heneghan and Kaasch.

Such findings help us to specify the meaning of 'populations' as the dominant IOs active in specific social policy fields, but potentially also for global social policy and governance in general. We can identify several patterns of how such fields are constituted and have developed over time. The fundamental distinction works along two dimensions: first, density and diversity focus on how many and what kind of IOs are active in a policy field. The concepts of density and diversity also address whether certain IOs have occupied particular niches within a policy field. Second, the interaction and relationship of the involved (IO) actors in a field can be characterized by either cooperation or contestation. Interaction and relationship also refer to the communication between IOs within a population as well as how IOs interact with the organizational environment of states, non-governmental organizations (NGOs), and other collective actors.

Prime examples of social policy fields which are densely populated by a diversity of IOs are education, as shown by Niemann and Martens, as well as the social policy dimensions of climate change, as elaborated by Lakeman. In both fields, we find a high number of IOs actively promoting 
their views and ideas. However, both fields also vary: while many of the IOs active in education are either distinct 'education' IOs or have been dealing with education as part of their mandate for a long time, climate change and its social dimension is a field which almost no IO seems to deny, and even IOs that have a distinctive thematic background and usually do not deal with matters of climate change have contributed to the discourse. In contrast, other fields are covered by a few specialized global IOs. Youth employment, as explored by Fergusson, is a policy field that is focused on a specific group and a specific labor market issue. With this example, we also see how global social policy studies are increasingly being organized into sub-fields. Their historical development is usually much shorter and the number of actors smaller-the ILO and World Bank commonly being the key players. According to Heneghan, both organizations have also largely shaped the global discourse on pension reform, although at different times and accompanied by a few UN organizations, the OECD, and the European Union (EU). In the case of children and their rights, Holzscheiter has argued that the centrality of the UN system and related organizations has become prevalent.

An important new finding for global social governance more generally that can be taken from the collection of chapters in this book is the significance of the United Nations Educational, Scientific and Cultural Organization (UNESCO). Although its focus is on education, science, and culture, UNESCO has been identified as an influential IO in various chapters. Besides being active in its core competency areas, UNESCO has also covered care and migration policies, disability, and even water issues. In fact, UNESCO was the first agency to deal with international health worker migration as an issue of global concern, as highlighted by reates and Pillinger. In the case of disability, Schuster and Kolleck underlined that UNESCO became a strong and active supporter of the Convention on the Rights of Persons with Disabilities (CRPD), adopting its own action plan for supporting persons with disabilities. Since its inception, UNESCO was involved in water politics, including the launch of UNESCO's International Hydrological Decade, as Schmidt demonstrated. Similarly, Fergusson elaborated that UNESCO has always been concerned with questions of youth (un)employment and has shaped the discourse in favor of raising the school leaving age. In light of its name and mandate, UNESCO has obviously been an important IO in the realm of education since its inception, although it is neither the only IO within the UN system nor the only education IO, as demonstrated by Niemann and Martens. 
The relationship between IOs within a policy field also differs significantly. On a continuum, this could range from cut-throat competition at the one pole to cordial cooperation on the other. However, in the case of social policy, we generally find that the typical contestations described for global social policies in the 1990s (Deacon et al. 1997) have not remained stable. Now, patterns of cooperation prevail over contestation in many global social policy fields. Even if IOs with very different worldviews and organizational backgrounds interact, like the OECD and the ILO for example, they still manage to agree on some common ground and do not escalate their diverging policy positions into permanent conflict. Two major causes for this development can be identified in the various case studies: global crisis and common (development) goals. For example, Mahon described in her chapter how after the global economic and financial crisis in 2008, the three major IOs in the realm of family policies- the ILO, the OECD, and the World Bank-embraced the concepts and language of inclusive growth and recognized women's unequal share of unpaid domestic work. As concerns the field of international health care workers, Yeates and Pillinger showed that the International Platform on Health Worker Mobility presents a recent example of cooperation between the ILO, the OECD, and WHO. This also mirrors the way in which the field of international health care workers is scattered across a variety of IOs which each look at it through a specific lens. According to Fergusson, the field of youth (un)employment is similarly characterized by recent IO partnerships, in which foremost the ILO and the World Bank collectively interpreted youth unemployment. It is too early to predict patterns of change or new structures in global social governance as a consequence of the COVID-19 crisis. However, the chapter by Kaasch identified some signs that at least global health governance might revert back to more individualized IO approaches. The role of the MDGs, SDGs, and other global initiatives, such as the Universal Health Coverage approach described in the chapter by Kaasch or the social protection floor initiative referred to in Heneghan's chapter, provides incentives to collaborate rather than to compete. Being part of such initiatives, not to mention heading specific gatherings or joint institutions, provides important leverage in related discourses.

Most of the IOs which were identified as dominant in social policies are global IOs. This means that their activities are not restricted to a particular region or set of countries. Usually, these global IOs are the 'big players'. However, in some social policy fields, regional IOs were also important and thus occupied their own particular niche. This has become particularly 
evident in the field of education, in which many IOs have a regional scope, as Niemann and Martens have shown. Despite the dominance of the UN system in the field of disability, regional approaches are now also visible. For example, Schuster and Kolleck demonstrated that the EU has a disability strategy and a focus on collecting information and data on the implementation status of the CRPD in member states. On the African continent and in the Southeast Asian region, IOs promoted and adopted additional instruments to mainstream the rights of people with disabilities. In the case of labor standards, Römer, Henninger, and Dung argued that regional organizations, such as the Association of Southeast Asian Nations (ASEAN) or the Southern Common Market (Mercosur), are better at coming to agreements and overcoming deadlocks since they represent more homogeneous groups of countries.

In addition, the field an IO is active in is also populated by other actors. Although other actors were not the focus of attention in our volume, it was impossible in some fields to describe the population of IOs without reference to other players, since their interconnection is deeply intertwined. The field of disability, as shown by Schuster and Kolleck, is a prime example, whereby the nexus between civil society actors and IOs is particularly strong in promoting and implementing the CRPD. The field of youth (un)employment, as explored by Fergusson, is characterized by partnerships between IOs, national governments, and also through partnershipbased entrepreneurial solutions. Similarly, in the field of labor standards, Römer, Henninger, and Dung showed that the implementation and enforcement of standards are deeply supported by a variety of actors, including multi-stakeholder initiatives, international unions, NGOs, and also grassroots movements. Furthermore, Holzscheiter argued that starting from the 1990s, the field of children's rights became densely populated by non-governmental, hybrid, and public-private partnership organizations as well as networks which all interact with each other. For education, Niemann and Martens reminded us that despite there being 30 IOs active in the field, some NGOs and think tanks can be more influential through their financial means than many of the education IOs with little budgets.

\section{Discourses IOs Spread about Social Policy Issues}

As has been shown, all analyzed social policy fields are populated by several IOs. These IOs do not necessarily hold the same preferences or convictions regarding the best policy solutions or the most desirable policy aims. Hence, sometimes IOs discursively compete for who gets their ideas 
accepted (Béland and Orenstein 2013). In analyzing the cognitive authority of IOs within a given policy field, it is important to take into account who is able to shape problem perceptions, goal definitions, and appropriate means. Since this generally reflects a soft governance approach, assessing how IOs disseminate their ideas within a discourse is crucial. Discourse dynamics (how framing in a social policy field varied over time) and discourse coalitions (consensus or diverging ideas) are two concepts that have been addressed throughout this volume. While the first aspect is tied to the changing nature of a global discourse in a social policy field, the latter refers to cooperation among IOs when putting forward their ideational framework. To recall, the concept of 'discourse' in this volume refers to the strategic way in which the collective actor IOs frame ideas. Analyzing the discourses which IOs promote allows for insights into their policies and leitmotifs, which shape particular social policy fields, and a better understanding of how views on social policies have evolved over time.

The discourses IOs promote are not static but changing: they have different facets and scopes in different times and contexts. As Heneghan showed for the case of pensions, the discourses IOs spread are shaped by paradigm shifts about global economics. Moreover, certain discourses can be highly connected with specific IOs. In the case of disability, as explored by Schuster and Kolleck, it is particularly striking that specific preferences are strongly interlocked with the involved IOs: while a medical approach to disability is promoted by $\mathrm{WHO}$ and involves enhancing welfare policies to support and 'medically repair' disabled individuals, a sociopolitical or rights-based approach to disability policymaking is favored by the UN system and implies an adjustment of the physical environments of disabled persons to suit their needs. The OECD and the ILO instead favor an economic model of disability by focusing on building and ensuring inclusive structures in the labor market. In the realm of family issues, Mabon demonstrated that discourses promoted by IOs were bifurcated until the economic crisis of 2008 between the North and the South, whereby the North connected with IOs such as the ILO and the OECD and followed the shift they promoted from the male breadwinner to adult earner caregiver model, whereas the South employed the policies of UNICEF and the World Bank which primarily targeted the children of poor families. After 2008 and with the introduction of the SDGs, both world regions have come to be addressed in a common discourse of inclusive growth. In 
the case of water policies, we have learned from the chapter by Schmidt that IOs contributed to the discourse on water being changed from one where it was seen as a natural resource to one where it is framed as a social good.

In some cases, discourses have become harmonized and previous contestation has been replaced by collaboration and associated agreement over ideas. The chapter by Römer, Henninger, and Dung illustrated the tensions and disagreements that importantly characterize the discourse on a set of adequate global labor standards across institutions. In fact, between and even within IOs, there are different viewpoints based on conflicting ideological beliefs on labor standards. In addition, there are also strong regional differences. The field of pensions has typically been described as a field of contestation of economic paradigms (neoliberal views vs. social investment), where IOs accordingly promote one or the other, as can be seen by the ILO's opposition to the neoliberal-leaning World Bank and OECD. The chapter by Heneghan told this same story too, but also provided evidence of global economic crises having an impact on economic thinking. Nowadays, the organizations collaborate under the roof of the Social Protection Inter-Agency Cooperation Board (SPIAC-B), and the discourse over appropriate pension reform happens with the aim of interagency agreement on key terms, ideas, and recommendations.

For the field of climate change and social policy, as dealt with in the chapter by Lakeman, the tensions between economic, environmental, and social goals are expected to lead to competing policy ideas and models. However, the field as such is currently only just beginning to emerge, and the engagement of IOs is still more focused on issues of climate change and its impact on social well-being than on establishing comprehensive eco-social policies. As Yeates and Pillinger have argued, some contestation also prevails in the area of health worker migration, where fracture lines within the cooperative Global Skills Partnerships have emerged and where the essential health needs and social protection approaches of the ILO and WHO have been challenged by proponents of mobility, financial incentives, employability, and skills transfers by the OECD and the World Bank. For global health governance regarding health care systems, Kaasch showed that it is the level of abstraction that produces dynamics of consensus or contestation, respectively.

It also became apparent that the discourse in one social field is often linked to the discourse in other fields of IO activity. For example, 
discussing disability rights is associated with preventing poverty and granting access to education for people with disabilities, as Schuster and Kolleck have shown. Similarly, children's rights also touch upon the topics of health, education, food security, and social benefits, according to Holzscheiter. In addition, social policy discourse can also be shaped by non-social policy issues: Schmidt pointed out that water policy discussed by IOs is also influenced by knowledge from engineering and technological progress. Also, the discourse on development policies contributed to how water was framed as a social good. In sum, the interlinkage between discourses could lead to new evaluations, goal definitions, or problem recognitions.

In several social policy fields, the authors have identified a current dominant double-edged discourse in the nexus between economic issues and social rights. In this context, the preferences and leitmotifs of IOs vary and the purpose of a given social policy is defined differently. This does not mean that IOs with different world views are necessarily irreconcilable with each other. It rather means that (groups of) IOs pursue different aims that in turn shape the whole discourse within a social policy field. In the case of care and migration, the dualism is reflected in the availability of health workers on the one hand and the quality of provisions on the other hand, as Yeates and Pillinger have argued. The discourse on education revolves around the following two education purposes: a means to generate human capital or a social right to promote citizenship values. While some IOs like the OECD or the World Bank primarily focus on the former, the ILO and UNESCO place education as a citizenship right at the center of their approach, according to Niemann and Martens. Fergusson highlighted in his study on youth (un)employment that the right to quality (vocational) training is sometimes plotted against considerations of employability (options) in the job market. Finally, in the discourse on children's rights, Holzscheiter claimed that a traditional approach to serving children's special needs by providing (financial) assistance is contrasted with a more progressive approach of recognizing children's rights as human rights.

In addition, the analyses in this volume also show that IOs may have divergent interpretations of a given concept depending on their specific angle. While food security in the Food and Agriculture Organization of the United Nations (FAO) has been associated with securing its production and fighting hunger, the World Bank's solution to food security has lain in providing financial access for consumption. From the perspective of 
the World Trade Organization (WTO), food security has instead been seen as a function of open markets and trade, as demonstrated by Wolkenhaner. Yeates and Pillinger showed in the case of health worker migration that even though underpinning ideas were shared by relevant IOs, the ideas were taken up in quite different ways. While the ILO, WHO, and UNESCO all subscribe to the UN's normative principles on human rights and equality, each IO blends in different perspectives which in turn reflect their specific fundamental discourses on improving working conditions and social justice (ILO), meeting essential health needs (WHO), or of emigration of highly skilled health workers (UNESCO). As elaborated by Holzscheiter, sometimes different views of global IOs and regional organizations become apparent in the discourse. Children's rights, as formulated in the UN Convention on the Rights of the Child (UNCRC) and interpreted by the Committee on the Rights of the Child (CRC), are challenged on the grounds of Western bias by regional human rights treaties and institutions, like the ASEAN Commission on the Rights of Women and Children which pays additional attention to a stronger cultural embedding of core principles and ideas codified in the UNCRC.

\section{Linking the Constellation of IOs to the Discourses THEY PROMOTE}

In sum, IOs have been shaping global social governance not only since recent times but for a century. Most exceptionally, the ILO is the most prominent IO in this regard and across all fields, but especially the World Bank and the OECD are among the dominant players too. Thus, IOs with universal membership, like the UN and UN agencies, have been shaping global discourses with great intensity. Hence, it is safe to say that IOs have held cognitive authority in the realm of social policy for a long time, and states not only tolerated but also encouraged the delegation of social policy authority to the international level long before it was considered necessary due to globalization processes and growing international interdependencies. IOs often exercise soft governance as broadcasters of new ideas. What has become evident from the contributions in this volume is that the general approach of IOs does not differ in social fields: While an economistic view is applied by the World Bank, the OECD, and to some extent the ILO, the UN system and other IOs apply social or rights-based approaches. 
The fact that IOs deal with social policy on a global scale, however, is no recent phenomenon. Although social policy is widely considered as a classical domain of the nation state, the internationalization of it began well before globalization. It even dates back to before World War II, and before many currently operational IOs were founded. As Schmidt reminded us, one of the first multilateral international agreements, the founding treaty of the Danube Commission of 1856 on water issues, also addressed social policy issues in the broader sense. A very early form of protecting children's rights was established back in 1904 with the International Agreement for the Suppression of 'White Slave Traffic', according to Holzscheiter. In the field of food policy, as we learned from the chapter by Wolkenhawer, the International Institute of Agriculture (IIA) was founded in 1905 as a global mechanism for networking as well as for exchanging information and statistics. The ILO, recently celebrating its centenary anniversary, started its social policy program in 1919 with Convention 003 on Maternity Protection, as explored by Mahon, and the Minimum Age Convention on youth employment, as explored by Fergusson. In the subsequent decades, the ILO continued to aim for the introduction of social protection mechanisms, for instance with the Conventions 35 and 36 , on old-age insurance in industry and agriculture.

However, intrinsic features of organizations may determine the kind of involvement an IO has as well as the nature of its discourse. Thus, in addition to the organizational environment, specific features of an IO have shaped the kind of discourses they promote and their ability to respond to a changing environment. As seen in the case of pensions, dealt with by Heneghan, the World Bank and the ILO have their own distinct departments on the issue and enjoy having the autonomy to promote specific pension models. Moreover, both organizations have the means to offer professional and technical assistance to reforming countries. Also, competition between sub-departments of single IOs influences how a discourse is shaped. For example, the discourse on family policy within the OECD was changed by the adoption of the initiative 'New Approaches to Economic Challenges', which posed direct challenges to the ideas of the Economic Department by enhancing the centrality of the Directorate for Employment, Labor and Social Affairs' organizational discourse, as Mahon has shown.

Furthermore, intrinsic features of IOs may also influence cognitive authority. For the case of labor standards, Römer, Henninger, and Dung have shown that unlike other IOs, the regulations passed by ASEAN 
remain non-binding with questionable impact due to the lack of regional harmonization. Since the OECD and the EU have a distinct membership, they are reluctant to promote one specific pension model and therefore prefer to use benchmarking as cognitive authority to promote general principles. According to Heneghan, reputation and cognitive authority also play a role in pension politics, as the tripartite structure of the ILO promotes the emergence of consensus. In the case of education policy, the cognitive authority of the OECD stems in particular from its data analysis department. The OECD's emphasis on gathering and interpreting data on education performance through its Programme for International Student Assessment (PISA) Study made the IO a central reference point for other IOs (and other stakeholders) in the discourse (Niemann and Martens 2018).

With this volume, our aim was to analyze global social governance as an architecture of arguments brought forward by the IOs active in various fields within the broader areas of labor and migration, family and education, and health and environment. The varying constellations of IOs in different social policy fields and their patterns of discourse that characterize global social policies have been explored. The volume brought forward interesting and new insights about IOs and their involvement in global social policies as summarized in this chapter. However, there are also many issues that remain:

First, we need to better understand additional policy fields that overlap with social policies. For example, trade, energy, or security policies would almost certainly reveal a social policy component. Hence, it is not the policy field per se that makes it a social policy field, but it is more a deliberate decision to perceive issues as a social policy.

Second, we could aim to find new ways to analyze patterns of collaboration and contestation by performing a more systematic analysis of fields and sub-fields in social policies. More concretely, characterizations of global labor market policies could be compared with and related to analyses of the sub-fields of labor market policies such as youth unemployment, migrant labor markets, and child labor; or analyses of different fields of global labor markets like the global food industry, the global carpets and rugs industry, and global care markets. There are already analyses of many such groups and fields, sometimes also addressing the role of IOs, but there is no systematic comparison between them as to what characterizes many or all sub-fields and what is specific to a particular aspect of global labor markets. 
Third, more theoretical questions would include considerations on whether different discourses are becoming more isomorphic. Delving deeper into such questions would result in a better conceptualization of the meaning of overlapping and merging policy fields, as opposed to current concepts of discourses becoming more similar. From there, we could further investigate the implications for actor constellations and inter-actor relationships, or more generally for global social governance architecture(s).

Fourth, more research into the types of IOs in global social governance, the ways in which they are dependent on (not just aware of or linked to) other global social policy actors, and the extent of this dependency is also important for understanding their roles, positions, and leeway for exerting influence. A prominent example is the strong involvement of the Bill and Melinda Gates Foundation with WHO activities, because it regularly causes criticism from outside observers. Comparatively, we know much less about other IOs and their involvement with and dependency on other actors.

Fifth, any further contribution to global social governance will certainly have to take into account the implications of the COVID-19 pandemic on the roles, positions, abilities, and power of IOs. In the context of declining multilateralism, a process that was already in motion prior to the outbreak, the future of IOs like WHO and UNESCO is anything but certain. Particularly at risk is their 'global' significance, while financial institutions and knowledge actors like the OECD might be found to have a more stable position in the long term beyond the crisis.

\section{REFERENCES}

Béland, Daniel, and Orenstein, Mitchell, 2013. "International Organizations as Policy Actors: An Ideational Approach." Global Social Policy 13 (2): 125-143.

Deacon, Bob. 2007. Global Social Policy and Governance. London: Sage.

Deacon, Bob, Michelle Hulse, and Paul Stubbs. 1997. Global Social Policy: International Organizations and the Future of Welfare. London: SAGE.

Deacon, Bob, and Alexandra Kaasch. 2008. "The OECD's Social and Health Policy: Neo-liberal stalking horse or balancer of social and economic objectives." In The OECD and Global Governance, edited by Rianne Mahon and Stephen McBride, 226-24l. Vancouver: UBC Press.

Deeming, Chris, Smyth, Paul, eds. 2018. Reframing Global Social Policy: Social Investment for Sustainable and Inclusive Growth. Bristol: Policy Press.

Ervik, Rune. 2009. "Policy actors, ideas and power: EU and OECD pension policies in Norway and the UK." In The Role of International Organizations in 
Social Policy. Ideas, Actors and Impacts, edited by Rune Ervik, Nanna Kildal and Even Nilssen, 138-164. Cheltenham: Edward Elgar.

Kaasch, Alexandra. 2010. "A New Global Health Actor? The OECD's Careful Guidance of National Health Care Systems." In Mechanisms of OECD Governance - International Incentives for National Policy Making?, edited by Kerstin Martens and Anja Jakobi, 180-197. Oxford: Oxford University Press.

Koivusalo, Meri, and Eeva Ollila. 1997. Making a Healthy World. Helsinki: Stakes. Mahon, Rianne. 2009. "The OECD's Discourse on the Reconciliation of Work and Family Life." Global Social Policy 9 (2): 183-204.

Mahon, Rianne, and Stephen McBride, eds. 2008. The OECD and Transnational Governance. Vancouver: UBC Press.

Mundy, Karen, and Antoni Verger. 2015. "The World Bank and the Global Governance of Education in a Changing World Order." International Journal of Educational Development 40 (1): 9-18.

Niemann, Dennis, and Kerstin Martens. 2018. "Soft Governance by Hard Fact? The OECD as a Knowledge Broker in Education Policy." Global Social Policy 18 (3): 267-283.

Open Access This chapter is licensed under the terms of the Creative Commons Attribution 4.0 International License (http://creativecommons.org/licenses/ by $/ 4.0 /$ ), which permits use, sharing, adaptation, distribution and reproduction in any medium or format, as long as you give appropriate credit to the original author(s) and the source, provide a link to the Creative Commons licence and indicate if changes were made.

The images or other third party material in this chapter are included in the chapter's Creative Commons licence, unless indicated otherwise in a credit line to the material. If material is not included in the chapter's Creative Commons licence and your intended use is not permitted by statutory regulation or exceeds the permitted use, you will need to obtain permission directly from the copyright holder.

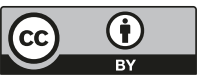

